DOI: $10.15587 / 2312-8372.2017 .109084$

\section{Prytula N., Prytula M., Boyko R.}

\title{
MATHEMATICAL MODELING OF OPERATING MODES OF UNDERGROUND GAS STORAGE FACILITIES
}

\begin{abstract}
Запропоновано математичні моделі газових потоків в основних технологічних об'єктах та модель структури підземного сховища газу. Приведені змістовні постановки режимно-технологічних задач та фактори впливу на точність їх розв'язування. Розроблено математичне забезпечення, результати апробацї якого підтвердили достатній рівень близькості розрахованих та заміряних режимних параметрів для всіх газосховищ України.
\end{abstract}

Ключові слова: математичні моделі газових потоків, підземне сховище газу, компресорна станиія.

\section{Introduction}

Underground gas storage facilities (UGS) in the gas transmission system (GTS) of Ukraine ensure the elimination of seasonal gas imbalance in the gas supply system of Ukraine. The main gas storage volumes in the UGS are in the west of Ukraine. This ensures reliable performance of contractual terms both in terms of volumes and pressure in the places where gas transit gas flows are received. Many factors influence the operation of the GTS and UGS. Among the main ones, one should point out the unevenness of both the withdrawal and the injection of gas. This significantly affects the basic operational parameters of the operation of both the GTS and the gas storage facilities. Underground gas storage facilities provide not only stable and reliable operation of the GTS, but also an important factor in optimizing the distribution of flows in the GTS. In conditions of a sharp increase in gas consumption and insufficient volume of imported gas, the only source of reliable and optimal operation of the gas transmission system, at significant intervals of time, is the active component of gas reserves in the reservoirs of gas storage facilities.

Effective UGS operation requires constant monitoring of well flow rates to prevent the destruction of their bottom-hole zones and formation of a cone of water flow, the inclusion in the operating mode of an optimal amount of facilities, reliable justification of the operation of ground facility for performance and pressure at the inlets and outlets of facilities and the like. These and many other problems require an operative and high-precision solution for their inclusion in decision-making systems - UGS and GTS dispatching control systems in general. The lack of such integrated products in the Ukrainian market, which were adapted to the existing technical, information support and available optimal scheduling systems, prompted their development.

\section{The object of research and its technological audit}

The object of research is gas-dynamic and filtration processes in facilities of gas transmission and storage.
The maximum realization of the optimization potential by the energy criterion requires the development of modeling and optimizing software complexes. Optimal UGS operation is considered from the point of view of optimal operation of the gas turbine and is ensured by: optimal operation of compressor stations, wells and gas collection system, optimal reservoir operation modes, and optimal organization of interaction of technologically coupled UGSs with each other and with GTS gas main pipelines in particular.

Based on the analysis of operating modes of individual process facilities, gas-hydroanalytical and field geophysical studies, which are given in the annual geological and technological reports on UGS operation [1], a number of reasons have been identified that significantly affect the operational efficiency of UGS, namely:

- from measurements of reservoir pressures in individual wells it is impossible to determine its distribution throughout the reservoir (this can only be established on the basis of adequate modeling of filtration processes);

- gas balance in porous media is calculated on the basis of pressure distribution, which depends on filtration, capacitive and geometric parameters and their setting is possible only in the process of solving identification problems;

- instability of finding the filtration resistances of bottom-hole zones is that the existing methodology does not take into account many parameters that significantly affect the calculation of well production. Among them, it is necessary to single out a constant change in the well supply area, anisotropy of the porous medium, replaceable thermo-hydraulic interference of the wells and change in filtration processes along the directions of their passage and magnitude, and the like.

When analyzing the materials of dispatching services of JSC «Ukrtransgaz» [1], problems with the operational analysis of UGS capacity were discovered. When assessing the UGS productivity, the actual distribution of pressures in the main gas pipelines was not taken into account. There were no operative estimates of the potential for their optimization for making decisions. These and other data are necessary to ensure the optimal GTS balancing. 


\section{The aim and objectives of research}

The aim of research is development of a system mathematical model that would include filtration and gas dynamic processes in UGS facilities, and develop methods for their analysis.

To achieve this aim, it is necessary to solve the following tasks:

1. To develop an integrated mathematical model of an underground gas storage facility with a complex structure of its technological scheme.

2. To formulate the regime problems of calculating the parameters of the filtration and gas flows in terms of the variable initial and boundary conditions.

3. To develop adaptive stable methods for solving systems of nonlinear equations and algorithms of minimal complexity for performing simulation and constructing optimal solutions for systems with objects of discrete action.

\section{Research of existing solutions of the problem}

Complexes of modeling technological chains, including all objects in the path of gas from the reservoir to the point of gas entry into the main gas pipeline, are mainly used in gas fields [2]. For this purpose, various software packages (PIPEPHASE of SimSci-Esscor, USA, OLGA2000 of Scandpower, Norway, PIPESIM of Schlumberger, USA) are used, which describe individual subsystems - wells, gas gathering networks, compressor stations, reservoir collectors and the like. Existing approaches have not yet been brought to the simulation of these systems as a single hydraulic system, taking into account all the features of its operation. The main problems that arise in the development of settlement procedures are the complexity of models and incompleteness of their information support [3-11]. There are significant difficulties in adapting models under conditions of existing uncertainty of parameters, especially reservoir systems.

Development of software modeling and optimizing complex requires taking into account the mutual influence of all facilities of gas storages and the implementation of automatic adaptation of models in conditions of changing operating modes and technological scheme. Equally important are the requirements for the accounting of regulatory operating documents, as well as for ensuring ease of implementation, operation and provision of simulation modes for various modifications of UGS facilities. Some studies [5-9] take into account the integrated approach to the calculation of the operating regimes of the «reservoir-pipeline» chain.

According to O2Consulting [4], the foreign software market for geophysical services, which is used at UGS, is divided among the largest international companies. The share of the largest international players in the market for software for geophysical services: Schlumberger $30 \%$, CGGVeritas, which includes Fugro-Jason and Hampson-Russell Software\&Services. These companies produce $15 \%$ of software, Paradigm - $10 \%$, Roxar $-7-10 \%$. To maintain market position, it is necessary to regularly invest in R\&D (for example, Schlumberger allocates 10-15\% of annual profit to R\&D, which is more than 600 million US dollars). They require compatibility of the software with the software of large developers (Schlumberger, Paradigm,
Roxar, CGGVeritas). There are also legislative barriers related to the need to obtain patents and licenses. Technological barriers are very complex.

This justifies the need to realize the Ukrainian potential for development of high-performance software.

\section{Methods of research}

Gas flow processes in such complex systems as UGS are described by gas-dynamic models in network-type structures and filtration models in inhomogeneous porous multilayered media with geological faults (equations of mathematical physics). Accounting for the operation of each gas compressor unit (GCU) of UGS is ensured by the representation of a compressor station (CS) in the form of imitation discrete models of algorithmic type.

Models are nonlinear equations and systems of equations. The model of the UGS structure is constantly changing, which induces a change in the model of the system, the initial and boundary conditions. Numerical methods and algorithms for solving such systems that would reliably and quickly work in the whole process technology area are missing or insufficiently studied. Therefore, in order to find the flow distribution parameters of gas, adaptive multiple iterative methods for solving problems in mathematical physics are proposed [10, 11].

\section{Research results}

The main processes in UGS are the processes of gas filtration in its reservoirs and in the bottom-hole zones of wells, which are essentially unsteady. The reservoir as an anisotropic porous medium is characterized by porosity, permeability, gas saturation, filtration coefficients, etc., as well as structural, geometric parameters, and they are all known approximately. In addition, the indicated parameters influence nonlinearly the gas filtration processes both in intensity and direction. During periods of a sharp increase in gas consumption, the reliability of GTS operation depends on the UGS capacity - the maximum possible gas sampling (peaking) per unit of time. This value is significantly affected, in particular, by the filtration parameters of the bottom-hole well zones. The possibility of changing the volumes of gas withdrawal and injection in significant volumes serves as an important tool for the GTS both for managing gas flows in the system of main gas pipelines and for optimizing the operational performance of the gas transmission system. At the UGS, there is various complexity of the gas collection system. Among them, individual (flow-lines of wells), and group (flow-lines-collector) systems are identified. Some parameters of objects in UGS are given in Table 1. The length of flow-lines and collectors varies from hundreds to several thousand meters. Other facilities - the gas treatment system includes gas purification and dehydration facilities. Gas storage facilities are provided with various types of compressors. Among them there are compressors of piston type and with centrifugal superchargers, with gas turbine and gas engine pretexts. They can operate under conditions of several degrees of gas compression (one to three).

Those models of objects, the realization of which allowed to make calculations of the basic regime problems with sufficient accuracy, are given in the article. Models 
of some objects can be complicated by taking into account the anisotropy of the bottom-hole zones and the reservoir as a whole. As practice shows, any complication of models that take into account parameters with problem identification can lead to instability of the calculation process, which in the end will lead to a significant discrepancy between the measured and calculated data.

$$
\frac{\partial}{\partial x}\left[\frac{k h}{\mu z} \frac{\partial p^{2}}{\partial x}\right]+\frac{\partial}{\partial y}\left[\frac{k h}{\mu z} \frac{\partial p^{2}}{\partial y}\right]=2 \alpha m h \frac{\partial}{\partial t}\left[\frac{p}{z}\right]+2 q(t) h p_{0} .
$$

Equations (1) on the boundary $\Gamma$ of the area $\Omega$ satisfy the boundary conditions:

- Dirichlet's condition on $\Gamma_{w}$ :

Table 1

The main object parameters of operating underground gas storage facilities

\begin{tabular}{|c|c|c|}
\hline Facilities & Object parameters & Parameter change interval \\
\hline Reservoirs-collectors & $\begin{array}{l}\text { Geometrical: reservoir surface } \\
\text { Filtration: porosity, } \\
\text { permeability }\end{array}$ & $\begin{array}{c}10-100 \mathrm{~km}^{2} \\
12-30 \% \\
300-2300 \mathrm{mD}\end{array}$ \\
\hline Bottom-hole zone & Coefficients of filtration resistance $(\mathrm{a}, \mathrm{b})$ & $\begin{array}{c}\left.\text { 0,3-22 (1/thous. } \mathrm{m}^{3} / \mathrm{d}\right)^{2} \\
0,01-2,5\left(1 / \text { thous. } \mathrm{m}^{3} / \mathrm{d}\right)^{2}\end{array}$ \\
\hline Wells & $\begin{array}{c}\text { Number of operational } \\
\text { Average depth } \\
\text { Intervention interval of the reservoir } \\
\text { Density of perforation, presence of bottom-hole filter }\end{array}$ & $\begin{array}{l}75-341 \text { items } \\
610-1500 \mathrm{~m} \\
10-60 \mathrm{~m} \\
8-22 \text { holes/l.m }\end{array}$ \\
\hline $\begin{array}{l}\text { Gas collection } \\
\text { systems }\end{array}$ & Individual and collector systems & $150-5600 \mathrm{~m}$ \\
\hline $\begin{array}{l}\text { Gas gathering sta- } \\
\text { tions, gas pre-treat- } \\
\text { ment facilities } \\
\text { (separation) }\end{array}$ & Productivity & 320-1100 thous. $\mathrm{m}^{3} /$ year \\
\hline ВСБ & $\begin{array}{c}\text { GPA } \\
\text { General power }\end{array}$ & $\begin{array}{c}6-28 \text { items } \\
22-322 \mathrm{MW}\end{array}$ \\
\hline $\begin{array}{l}\text { Integrated gas treat- } \\
\text { ment plants }\end{array}$ & General power & 320-5500 thous. $\mathrm{m}^{3} /$ year \\
\hline $\begin{array}{l}\text { Gas accounting } \\
\text { systems }\end{array}$ & Performance & $320-5500$ thous. $\mathrm{m}^{3} /$ year \\
\hline
\end{tabular}

$p\left(x_{i}, y_{i}\right)=p_{i}, \quad\left(x_{i}, y_{i}\right) \in \Gamma_{w} ;$

- the Neumann condition on $\Gamma_{2}$ :

$\Phi p(x, y)=$ $=\frac{k \cdot h}{\mu \cdot z} \frac{\partial p}{\partial x} v_{x}+\frac{k \cdot h}{\mu \cdot z} \frac{\partial p}{\partial y} v_{y}=0$,

$(x, y) \in \Gamma_{2}$,

where

$$
v_{x}=\cos (v, x), \quad v_{y}=\cos (v, y)
$$

is the components of the vector $\mathrm{v}$ - the outer normal to the $\Omega \subset R^{2}$; $k(x, y, p), m(x, y), h(x, y)-$ coefficients of permeability, porosity, gas-saturated thickness of the layer, respectively; $q(t)$ - source function; $z$ - coefficient of compressibility; $\mu$ - coefficient of dynamic viscosity; $p_{0}-$ air pressure in atmospheric conditions.

The mathematical model of UGS [5-9] is formed on the basis of object models, which are combined into a single hydraulic model according to the technological scheme. The heterogeneity of mathematical models of objects makes it difficult to develop iterative procedures for reconciling the parameters of gas flow within neighboring objects. The less the matching points of the gas flow parameters available in the model, the faster and more stable the iterative calculation procedure will be. The existing modeling complex provides for the coordination of parameters at the boundaries - reservoir - the bottom-hole zone and the gas gathering station - the compressor station.

6.1. Mathematical model of gas filtration. In the region $\Omega$ at points with coordinates $\left\{x_{i}, y_{i}\right\}, \quad i=1, \ldots, n$ the pressure values (reservoir pressures in the area of the location of operational and observation wells) are given. Let's consider a layer as an area $\Omega^{*}$, the thickness of which $h(x, y)$ is much less than its other geometric dimensions. In connection with this, let's consider this region as two-dimensional $\Omega$ with a contour $\Gamma$. The Cartesian coordinate system is chosen so that the axis $\mathrm{Oz}$ is directed vertically upward (opposite to the gravitational forces). From the filtering area, let's exclude areas around the points $\left\{x_{i}, y_{i}\right\} i=1, \ldots, n$, where the wells are located. Therefore, the boundary $\Gamma$ consists of $\Gamma_{w}$ $(i=1, \ldots, n)$ and $\Gamma_{z} \quad\left(\Gamma=\Gamma_{w} \bigcup \Gamma_{z}\right)$, so

$$
\Gamma_{w}=\bigcup_{i=1}^{n} \Gamma_{i}
$$

During the filtration, the gas pressure $p(x, y, t)$ is determined by the equation:
Withdrawal (injection) of gas from underground storage facilities is carried out through wells located at points $\left(x_{i}, y_{i}\right)$ for a certain period of time $t \in\left[t_{1 i}, t_{2 i}\right], \quad(i=\overline{1, n})$. The density of withdrawal is determined by the formula:

$$
q(t)=\frac{1}{V} \sum_{i=1}^{I} q_{i} \delta\left(x-x_{i}\right)\left(y-y_{i}\right)\left[\eta\left(t-t_{1 i}\right)-\left(t-t_{2 i}\right)\right],
$$

where $q_{i}$ - gas withdrawal from the i-th well; $\delta(x)-$ Dirac delta function; $\eta\left(t-t_{j i}\right)-$ Heaviside unit function; $V$ - volume of the gas storage.

6.2. Model of gas inflow in the bottom-hole well zone. It is believed that the gas from the storage enters the bottom-hole area of the well with a spherical law and can be represented by the equation:

$$
-d\left(\frac{p}{p_{0}}\right)^{2}=\frac{\mu}{\pi h k p_{0}} \frac{q_{0}}{F} d F+\beta \frac{\rho_{0}}{\pi p_{0} d h} \frac{q_{0}^{2}}{F^{2}} d F,
$$

where $p_{0}, q_{0}, \rho_{0}$ - pressure value, well production rate and gas density under normal conditions; $F$ - the surface area of the filtration; $h$ - reservoir thickness.

The coefficient of vortex resistance is the least studied. In work [12], data are presented from the calculation of the coefficient of vortex resistance during the filtration of gas in the reservoir, which is formed from four grain sizes (3.1 to $0.42 \mathrm{~mm}$ ). The processing of these data showed that the coefficient $\beta$ is approximately equal to one. In particular, there are such representations of the coefficient $\beta$ [12].

$$
\beta=\frac{12 \cdot 10^{-5} d^{3}}{m k^{3 / 2}}, \quad \beta=\frac{0.22}{\left(m-m_{0}\right)^{2.5}},
$$




$$
\beta=\frac{3.5 \times 10^{-2}}{m^{1.5} k_{g}{ }^{1.5}}, \quad \beta=\frac{7.4 \times 10^{-12}}{k},
$$

where $m\left(m_{0}\right)$ - the coefficients of open (closed) porosity; $k_{g}$ - gas saturation coefficient; $k$ - permeability coefficient; $d$ - grain diameter of the rock.

To determine the coefficient $\beta$, the macro-roughness coefficient 1 can be used. In [11], a graph of the results of experimental studies in the coordinates $\lg (1 / l)-l g k$ is given. In the first approximation, the relationship between $\mathrm{l}$ and $\mathrm{k}$ has the form:

$$
l=\frac{k^{1.45}}{7.4 \times 10^{-12}} .
$$

For uniformly anisotropic formations, reservoir pressure $P_{r}$ and bottom-hole $P_{c}$ pressure are related by:

$$
P_{r}^{2}-P_{c}^{2}=A Q+B Q^{2} .
$$

In the case of isotropic reservoirs, the coefficients of the filtration resistance will be:

$$
\begin{aligned}
& A=\frac{\mu z p_{0} T_{r}}{\pi k h T_{0}}\left(\ln \frac{R_{k}}{r_{c}}\right), \\
& B=\beta \frac{\rho_{0} z p_{0} T_{r}}{2 \pi^{2} h^{2} \sqrt{k} T_{0}}\left(\frac{1}{r_{c}}-\frac{1}{R_{k}}\right),
\end{aligned}
$$

where $R_{k}$ - cavity radius; $T$ - gas temperature; $R$ - gas constant; $z$ - gas compressibility coefficient; $\rho_{0}-$ gas density under normal conditions; $M$ - coefficient of gas dynamic viscosity in reservoir conditions; $P o$ and $T o-$ pressure and temperature under normal conditions; $P_{O}=1.013 \cdot 10^{5} \mathrm{~Pa} ; T_{0}=273 \mathrm{~K} ; T_{r}$ - the average temperature in the reservoir; $\mathrm{z}$ - the average streak coefficient of the gas in the reservoir; $k$ - permeability coefficient; $\beta$ vortex resistance coefficient; $h$ - reservoir thickness; $r$ the radius of the borehole along the chisel; $R_{k}$ - radius of the drainage zone.

For analysis of the quality evaluation of the bottom-hole zone opening and modeling of the gas flow to the well, the following formula can be used:

$$
p_{r}^{2}-p_{b}^{2}=A q_{0}+B q_{0}^{2}, A=\frac{A_{1}}{k_{r}}+\frac{A_{2}}{k_{b}}, B=\frac{B_{1}}{k_{r}^{3 / 2}}+\frac{B_{2}}{k_{b}^{3 / 2}},
$$

where

$$
\begin{aligned}
& A_{1}=\frac{\mu p_{0}}{\pi h_{x}} \ln \frac{R_{k} h}{R_{c} h_{x}} ; \\
& A_{2}=\frac{\mu p_{0}}{\pi h_{x}} \ln \frac{R_{c}}{r_{k 1} l_{k 1} n_{01}+r_{k 2} l_{k 2} n_{02}} ; \\
& B_{1}=12 \cdot 10^{-5} \frac{\rho_{0} p_{0}}{2 \pi^{2} h_{x}} \frac{d^{2}}{m}\left(\frac{1}{R_{c} h_{x}}-\frac{1}{R_{k} h}\right) ; \\
& B_{2}=12 \cdot 10^{-5} \frac{\rho_{0} p_{0}}{2 \pi^{2} h_{x}^{2}} \frac{d^{2}}{m}\left(\frac{1}{r_{k 1} l_{k 1} n_{01}+r_{k 2} l_{k 2} n_{02}}-\frac{1}{R_{c} h_{x}}\right) ;
\end{aligned}
$$

$R_{c}$ - radius of the boundary of the bottom-hole zone; $h$ - average thickness of the reservoir;
$R_{k}$ - radius of the power circuit;

$h_{x}$ - the height of that part of the casing that is perforated and the perforations have parameters $n_{01}, r_{k 1}, l_{k 1}$ and $n_{02}, r_{k 2}, l_{k 2}$, where $r_{k i}, l_{k i}$ are the radii and lengths of the perforations, and $n_{0 i}-$ the perforation density $(i=1,2)$.

6.3. Mathematical model of gas flows in pipeline sections [10]. Since the process of collecting gas passes through a system of pipelines, there is a need for their hydraulic calculation. It is known that the gas collection system at UGS uses medium diameter pipes and up to several kilometers in length. Accordingly, it is possible to assume that the process of gas flow in such system is steady and isothermal. In this case, the parameters of the gas flows in the pipes satisfy the equation:

$$
\frac{\partial}{\partial x}\left(p+\rho v^{2}\right)=-\rho\left(\frac{\lambda v|v|}{2 D}+g \frac{d h}{d x}\right)
$$

where $v$ - gas flow rate; $D$ - internal diameter of the pipeline; $d h$ - change of the elevation mark of the pipeline laying; $\lambda$ - hydraulic resistance coefficient; $g$ - acceleration of gravity; $x$ - current coordinate $x \in[0, l] ; l-$ length of the pipeline.

For calculation of flow-line-collector systems in the places of pooling and branching of flows, the equation of mass flow balance is fulfilled:

$$
\sum_{i} m_{i j}+\sum_{k} m_{j k}=0, j \in V
$$

6.4. Modeling of the operating modes of the compressor station [11]. CS model is formed on the basis of the structure model and the models of its facilities. The structure model is represented in the form of a graph in which objects that have a length are represented by edges and all others by vertices. The main object is the gas-compressor unit (GCU), is represented by a drive and a centrifugal supercharger (CS). It is known [11] that the parameters of the gas at the input and output of the CS link a set of empirical dependencies.

$$
\begin{aligned}
& \varepsilon=\varphi_{1}\left([q]_{p r},\left[\frac{n}{n_{n}}\right]_{p r}\right), \\
& \eta_{p o l}=\varphi_{2}\left([q]_{p r}\right), \\
& \frac{N_{i}}{\gamma_{n}}\left(\frac{n_{n}}{n}\right)^{3}=\varphi_{3}\left([q]_{p r}\right), \\
& N_{e}^{p}=N_{e}^{n} K_{N e}\left(1-K_{t} \frac{t_{0}-t_{0}^{n}}{t_{0}+273}\right) \frac{p_{a}}{0,1033}, \\
& {\left[\frac{n}{n_{n}}\right]_{p r}=\frac{n}{n_{n}} \sqrt{\frac{z_{p r} R_{p r} T_{p r}}{z R T},}} \\
& {[q]_{p r}=\frac{n_{n}}{n} q .}
\end{aligned}
$$

The remaining operating parameters of the gas compressor unit are found by the formulas: 


$$
\begin{aligned}
& q_{p}=q_{p}^{n} K_{t}\left(0,75 \frac{N_{e}}{N_{e}^{n}}+0,25 \sqrt{\frac{t_{0}+273}{t_{0}^{n}+273} \frac{p_{a}}{0,1033}}\right), \\
& q_{p}^{n}=\frac{860 N_{e}^{n}}{\eta_{e}^{n} Q_{n} 10^{3}}, \\
& N_{e}=N_{i}:\left(\eta_{m} K_{N}\right),
\end{aligned}
$$

where $n$ - CS turnover; $q$ - gas flow through CS; $\eta_{p o l}-$ polytropic efficiency of CS; $q_{p}^{n}-$ nominal fuel gas consumption; $\varepsilon$ - compression ratio; $N_{e}^{n}$ - rated power of the gas turbine unit (GTU); $K_{N e}-$ coefficient of technical condition of gas turbine units (GTU); $K_{N e}-$ coefficient that takes into account the influence of ambient air temperature; $t_{0}$ - air temperature at the inlet to the GTU; $t_{0}^{n}-$ nominal air temperature at the inlet to the gas turbine unit; $p_{a}$ - absolute atmospheric air pressure as a function of altitude $\mathrm{H} ; t_{0}-$ air temperature in ${ }^{\circ} \mathrm{C}$ at the entrance to the GTU; $N_{i}$ - internal power of CS; $Q_{n}$ - nominal lower specific heat of fuel combustion; $\eta_{e}^{n}-$ nominal GTU efficiency; $\eta_{m}$ - mechanical efficiency; $K_{N}$ - technical condition in terms of capacity; $z_{p r}, R_{p r}, T_{p r}$ gas parameters, in which experimentally determined characteristics of the supercharger; $\gamma_{c}-$ specific weight of gas at standard conditions $(P=0.1033 \mathrm{MPa}, T=293 \mathrm{~K})$; $n_{n}$ - the rated speed of the supercharger; $\varphi_{k}(k=1-3)$ are empirically established functions.

The given characteristics allow to take into account: the deviation of the gas parameters at the inlet of the supercharger $\left(z_{i n}, R, T_{i n}\right)$ from their reduced values $\left(z_{p r}, R_{p r}, T_{p r}\right)$, the deviation of the actual speed of the supercharger from its nominal value $n_{n}$.

The value of the polytropic efficiency $\eta_{p o l}$ is found from the relation:

$$
T_{\text {out }} z_{\text {out }}=T_{\text {in }} z_{\text {in }} \varepsilon^{\frac{k-1}{k \cdot \eta_{\text {pol }}}}
$$

and refined, using the known values $\varepsilon$ and $n$ using the formula:

$$
\varepsilon^{\frac{k-1}{k \eta_{p o l}}}=\left(\frac{n}{n_{n}}\right)^{2} \frac{z_{p r} T_{p r} R_{p r}}{z_{i n} T_{i n} R}\left(\varepsilon_{n}^{\frac{k-1}{k \eta_{p o l}}}-1\right)+1 .
$$

To calculate the internal power of a centrifugal supercharger, let's use the well-known formula:

$$
N_{i}=\left(\frac{n}{n_{n}}\right)^{3} \rho \frac{m z_{p r} T_{p r} R_{p r} q_{p r}}{(m-1) \eta_{p o l} 60}\left(\varepsilon_{n}^{\frac{m-1}{m}}-1\right),
$$

where $m$ - the polytropic coefficient.

There is a set of technological limitations for:

- position of the working points on the CS characteristics to ensure the unattended operation of the gas compressor unit;

- maximum volumetric productivity of CS;

- rotational speed of the CS shaft $\left(n_{\min } \leq n \leq n_{\max }\right)$;

- maximum power of GCU GTU;

- the maximum outlet pressure of CS, which is determined by the strength of the pipelines at the CS;

- maximum temperature at the CS outlet;

- minimum pressure value at the outlet of each CS;
- conditions associated with a given level of stability of the GCU operation (remoteness from the surging zone);

- conditions for the consistency of the CS connection scheme with the supply and discharge flow-lines and main gas pipelines.

6.5. Mathematical model of the structure of «main gas pipeline - bottom-hole well zone» technological chain. Let's imagine the technological scheme of the reservoir-pipeline by the graph $G(E, V)$. Each edge $(i, j) \in V$ of the graph has its own type $G(E, V)$. The type of the edge corresponds to a process object or a hydraulic equivalent. The following types of edges are included in the «bottom-hole zone collector» technological chain $\left(i_{\Gamma i}, i_{z i}, i_{s i}, i_{0 i}, i_{s h i}\right) \quad(i=1, \ldots, n)$ : bottom-hole zone $\left(i_{\Gamma i}, i_{z i}\right)$, well $\left(i_{z i}, i_{s i}\right)$, well piping $\left(i_{s i}, i_{0 i}\right)$, flow-line or well collector $\left(i_{0 i}, i_{\text {shi }}\right)$. The area of the bottom-hole zone $i_{\Gamma i}$ is considered homogeneous in terms of the «permeability» parameter. All the vertices belong to the circular contour $\Gamma_{i}$ of the bottom-hole zone. The pressure in these peaks is called the reservoir for the $i$-th well. The technological scheme, which includes a collector system, gas gathering stations, booster compressor station and connecting gas pipelines, forms a graph having also other types of edges. Each type of edge corresponds to its own model of gas flow.

It is assumed that the feeding area of each well is in the form of a circle. The radius of such circle is approximately half the distance to the nearest well. A circular zone, in the center of which there is a well, and in which the violation of Darcy's linear law occurs, is called the bottom-hole zone.

The resulted models of facilities give the chance to carry out the analysis of influence of factors on well production. The main factors are: borehole supply circuit, reservoir permeability, eddy currents, anisotropy of the bottom-hole zone and spatial anisotropy of the reservoir, macroroughness, mutual influence of the wells, density and parameters of perforations, etc. The high degree of uncertainty and complex correlation factors is affected the possibility of factor evaluation.

There is a set of direct and inverse problems. The direct tasks are those for which the calculation process is carried out in the direction - from the formation to the entrance of the BCS and, if necessary, to the main gas pipeline. If the input data is the pressure or flow rate at the input of the BCS or gas pipeline, and it is necessary to calculate the reservoir pressure in the loop region wells supply, then the problem is called feedback.

The system allows to find the flow rate of each well when setting pressure or costs for gas condensate fuel with additives. When setting the pressure on the gas condensate fuel with additives, there is its flow rate and vice versa, when setting the flow, there is pressure. Thus it is considered that one of the listed values is known - the average reservoir pressure in the sampling area, formation pressure in the area of each well, the total production rate of wells, the production rate of each well.

The distribution of reservoir pressure is significantly affected by the main parameters of the reservoir (porosity, permeability, effective power, geological, geometric, etc.), which are generally known approximately. For this, usually the input parameters satisfy the corresponding mathematical equations and systems also approximately. It is problematic to identify all these parameters separately. Geometric, filtration and geophysical parameters 
are interrelated in the reservoir. They can't always be found with sufficient accuracy. At the same time, there is no need to obtain the results of solving many mode problems with guaranteed accuracy.

The above-mentioned solved problem makes it possible to identify the parameters of the models from measurements of reservoir pressures, pressures and gas consumption at the boundaries of the objects of the technological chain «reservoir - main gas pipeline». The following procedure for identifying the parameters of the system models with retrospective data obtained for several seasons of UGS operation is proposed:

- refinement of geometric $(x, y, h(x, y))$ parameters is carried out by a scale factor, and open porosity - by the gas balance at neutral operation periods;

- calculation of permeability parameters of individual regions, zones and isolated layers and interlayers, the quality of opening bottom-hole zones or areas of open perforation;

- calculation of average permeability of near zones, or filtration resistances of bottom-hole well zones;

- calculation of the average efficiency of drives and polytropic efficiency of BCS centrifugal blowers.

The choice of the two-dimensional model of gas filtration is justified by the insignificant thickness (mostly tens of meters) of the gas-bearing formation in comparison with other geometric dimensions $(\mathrm{km})$ Most of them can be divided into a working and a peripheral zone for a number of parameters. Numerical experiments have shown that such assumption provided sufficient accuracy of modeling of filtration processes in such formations. The experience of identification of parameters of UGS reservoirs from pressure measurements in control wells, verified on real data, showed that such measurements do not always adequately react to changes in the average characteristics of the zone of their placement.

Particular attention is paid to bottom-hole well zones. The resulted models allow to realize a various degree of detail of processes in the near and directly in the bottom-hole well zones.

Calculation of gas flow in the bottom-hole zone, wells and gas gathering systems is carried out by an integrated model, which is implemented for distribution networks taking into account a set of characteristics, including relief of the laying route for flow-line and gas pipelines.

UGSs have GCU as a piston type with a gas engine drive, and with centrifugal superchargers with a gas turbine drive. There is a different degree of implementation of BCS parameters in software systems. The implementation is carried out both on detailed technological schemes and simplified ones. It is also necessary to permanently identify the parameters that will allow to accurately calculate the fuel-energy and regime parameters.

The process of adaptation of the reservoir filtration model is carried out every few years on operational and geophysical data, hydrodynamic studies of wells and calculated average pressure for the pressure measured by the gas pressures at the wellheads of individual wells (annular and buffer).

Pressure losses in the bottom-hole zone and well tubing require knowledge of filtration coefficients or permeability coefficients of the near and far zones. Other factors are the hydraulic resistance of the tubing string, the magnitude of the geothermal gradient, the pressure drop in the piping and the quality of the perforation of the production string are established during the course of numerical experiments on real measured data. In individual wells, the pressure loss may also depend on the presence of filters. In the UGS model, complex gas treatment units consist mainly of hydraulic equivalents (pressure losses depending on the gas flow rate).

A quantitative characteristic of the modeling process, which is used to solve certain regime problems, is given in Table 2.

Table 2

Qualitative and quantitative characteristics of the developed software

\begin{tabular}{|c|c|c|c|c|}
\hline $\begin{array}{c}\text { The object of } \\
\text { research }\end{array}$ & Object characteristic & Task & $\begin{array}{c}\text { Simulation time (the } \\
\text { duration of the process } \\
\text { that is modeled) }\end{array}$ & $\begin{array}{c}\text { Accuracy } \\
\text { of results }\end{array}$ \\
\hline Compressor station & $\begin{array}{c}\text { Five guild with } \\
28 \text { GCU }\end{array}$ & $\begin{array}{c}\text { Calculation of the C5 opti- } \\
\text { mum operating mode }\end{array}$ & $\begin{array}{c}15.0 \text { seconds (instanta- } \\
\text { neous value) }\end{array}$ & $<1 \%$ \\
\hline $\begin{array}{c}\text { Inhomogeneous gas } \\
\text { reservoir }\end{array}$ & $\begin{array}{c}\text { Two-dimensional gas } \\
\text { filtration, which takes } \\
\text { place on an area of } \\
\text { about 100 km² }\end{array}$ & $\begin{array}{c}\text { Calculation of the distribu- } \\
\text { tion of reservoir pressure } \\
\text { by the specified daily } \\
\text { volumes of injection and } \\
\text { withdrawal of gas }\end{array}$ & $\begin{array}{c}18.8 \text { seconds (5 years } \\
\text { of gas injection and } \\
\text { extraction process) for } \\
1825 \text { iterations of the } \\
\text { method work }\end{array}$ & $<0.1 \mathrm{MPa}$ \\
\hline $\begin{array}{c}\text { The technological } \\
\text { chain (reservoir, } \\
\text { bottom-hole zones, } \\
\text { wells, gas gathering } \\
\text { system) }\end{array}$ & $\begin{array}{c}4 \text { types of objects } \\
\text { by the mathematical } \\
\text { representation of } \\
\text { their models. }\end{array}$ & $\begin{array}{c}\text { To find its pressure for } \\
\text { medium-reservoir pressure } \\
\text { and consumption for } \\
\text { gas condensate fuel with } \\
\text { additives }\end{array}$ & $\begin{array}{c}0.8 \text { seconds (instanta- } \\
\text { neous value) }\end{array}$ & $<0.08 \mathrm{MPa}$ \\
\hline
\end{tabular}

When considering Table 2 it must be borne in mind that the accuracy of modeling is affected by the accuracy of identification of model parameters. The accuracy of the obtained results with imitation models depends also on the complexity of the algorithms, which is adjustable. In all cases, it is necessary to find a compromise between the accuracy of the simulation and the time it takes.

\section{SWOT analysis of research results}

Strengths. The strengths of the implemented project:

1. The two-dimensional filtration model of the reservoir ensured high modeling accuracy in time, several orders of magnitude less than the required for reservoir modeling in the three-dimensional view.

2. Numerical method - the method of finite elements, the elements of which are obtained as a result of triangulation of the formation's surface and whose dimensions were formed depending on the permeability, porosity and thickness of the reservoir, provided a significant reduction in the dimension of the systems of equations and, accordingly, the time for solving it. In addition, for the speed of obtaining the result, a method for solving systems of equations with essentially sparse matrices is developed. This provide the possibility of modeling the filtration processes in a matter of minutes, which take place in areas of tens of $\mathrm{km}^{2}$ and over a period of tens of months. 
3. CS discretely continuous algorithmic model ensured the calculation of its operating modes in the entire range of the regime parameters change, eliminated the problem of convergence of the method, and also provided access to the regime parameters of each of CS facilities. This provided access to the performance control parameters of each GCU and CS as a whole. This approach allowed to build an effective system for identifying the parameters of object models and facilitated the formulation and solution of a complete set of optimization problems.

4. An integrated mathematical model of objects and a method for solving systems of non-linear non-gradient type with a different mathematical representation of the equations have been provided, with guaranteed convergence, the ability to find the parameters of gas flows in all objects involved in the calculation.

5. The simulation process can start with some averaged input data and does not require their allocation in a system of process objects. The system forms the necessary boundary conditions for the problems of mathematical physics without user intervention.

6. What was said in 1-4 allowed to set and solve all necessary direct and inverse problems, including optimization ones, and ensured the inclusion of the UGS model in the single GTS model.

Weaknesses. To the essential weaknesses of the project is the insufficient level of ease of use of all realized capabilities of the created product. It is desirable to develop for many classes of tasks fairly simple and effective information and interface support, which does not require the user to have deep knowledge of the subject area.

Opportunities. The system allows to:

- assess the potential for optimizing the operation of the storage facility and the resources required for its implementation;

- study of the efficiency of operation of objects and bottlenecks under conditions of maximum loads on the system;

- study of the extreme characteristics of UGS in the GTS structure;

- optimal scheduling of the operation at the stages of injection and withdrawal of gas and its efficient operation under conditions of changing input parameters;

- assess the effect of the introduction of energy-saving measures and on the reconstruction of facilities or its replacement for another.

The task of UGS optimization (to assess the optimization potential and the parameters of the best regime) by the energy criterion is a problem with limited resources. Optimality of UGS operation, in the real conditions of its operation, can be achieved in the process of optimizing the work of both individual objects and the system as a whole. The calculation of optimal regimes in the process of its modeling is helped to identify and ensure the implementation of the available optimization potential. Some estimates of the possible effect are given in Table 3 .

Threats. In operating modes of off-line modeling complex, the main threat is the introduction of incorrect input data, which is not enough to provide the modeling process, and in other modes (on-line, real-time) the main danger is a failure in the telemetry system (SCADA type).
Table 3

Results of operation modeling of underground gas storage facilities and its objects on real data

\begin{tabular}{|c|c|}
\hline Measures & $\begin{array}{c}\text { Saving of fuel } \\
\text { gas in \% }\end{array}$ \\
\hline Minimizing the number of working GPUs & $3-11$ \\
\hline Ensuring maximum pressure at the CU output & $2-3$ \\
\hline Change in the distribution of costs between similar GPUs & up to 1 \\
\hline $\begin{array}{c}\text { Redistribution of flows between shops of } \\
\text { multipurpose C5 }\end{array}$ & $6-8$ \\
\hline $\begin{array}{c}\text { Timely transition from a 2-3-stage gas compression to } \\
\text { a 1-2-stage gas compression }\end{array}$ & up to 23 \\
\hline $\begin{array}{c}\text { Control of the temperature regime (cooling of the gas at } \\
\text { the outputs of the compressor) }\end{array}$ & up to 10 \\
\hline Non-compressor operation of UG5 & up to 4 \\
\hline
\end{tabular}

\section{Conclusions}

1. An approach is proposed to construct a model of the investigated system with a complex technological scheme, which structure is described in terms of graph theory and which includes models of diverse physical processes of continuous and discrete action.

2. The object is presented in terms of graph theory, which provided automation of the process of building a model of the system when its technological scheme is changed (the type of graphic object has the property - model). To assess the effect of modernization, it is sufficient to edit the flow sheet and, if necessary, to change the models of individual graphic objects. The methods and algorithms for implementing the system model and optimizing the processes that they undergo remain unchanged. Such means of representing the object provided, in terms of graph theory, the ability to effectively solve and solve a fairly complete set of regime problems.

3. Developed methods of non-gradient type ensure the guaranteed and rapid convergence of the iterative procedures. Traditionally, in such cases (solutions of systems of nonlinear equations), modified Newtonian methods are used, the convergence of which depends both on the initial approximation and on the smoothness and continuity of the processes. Real processes do not possess such properties (there are jumps and continuity). The proposed methods of discrete optimization of processes in which continuous and discrete action processes are present. They ensure the optimization of processes in conditions of the impossibility of calculating the necessary gradients, which classical methods require.

4. Approbation of the developed software is carried out during its long-term operation. The accuracy of modeling the UGS operation depends on the accuracy of identifying the parameters of its object models. The accuracy of calculating the average pressure is comparable with the accuracy of its measurement. In real conditions, the achievable accuracy of simulating the CS is within one percent. The modeling complex supports high accuracy of calculation of regime parameters during 3-5 years of modeling of processes in UGS without specification of identification parameters of object models. 


\section{References}

1. Zhurnal «Truboprovidnyi transport» [Electronic resource] // JSC «Ukrtransgaz». - Available at: \www/URL: http://utg. ua/utg/media/tt-journal.html

2. Rotov, A. A. Modelirovanie rezhimov raboty gazovogo promysla kak edinoi termogidravlicheskoi sistemy [Text] / A. A. Rotov, A. V. Trifonov, V. A. Suleimanov, V. A. Istomin // Gazovaia promyshlennost'. - 2010. - No. 10. - P. 46-50.

3. Buzinov, S. N. Raschet tehnologicheskoi tsepochki plast-skvazhina-shleif-KS-soedinitel'nyi gazoprovod pri tsiklichesko ekspluatatsii PHG [Text] / S. N. Buzinov, G. F. Tolkushin / Transport i hranenie gaza. - 1980. - No. 7. - P. 13-20.

4. Official Website of Schlumberger [Electronic resource]. - Available at: \www/URL: http://www.slb.com/

5. Peaceman, D. W. Interpretation of Well-Block Pressures in Numerical Reservoir Simulation(includes associated paper 6988) [Text] / D. W. Peaceman // Society of Petroleum Engineers Journal. - 1978. - Vol. 18, No. 3. - P. 183-194 doi:10.2118/6893-pa

6. Aavatsmark, I. Well Index in Reservoir Simulation for Slanted and Slightly Curved Wells in 3D Grids [Text] / I. Aavatsmark, R. A. Klausen // SPE Journal. - 2003. - Vol. 8, No. 1. P. 41-48. doi:10.2118/75275-pa

7. Katz, D. L. Underground Storage of Fluids [Text] / D. L. Katz, K. H. Coats. - Ulrich's Book Inc, 1968. - 575 p.

8. Tek, M. R. Natural Gas Underground Storage: Inventory and Deliverability [Text] / M. R. Tek. - Tulsa: PennWell Publishing, 1996. - $375 \mathrm{p}$

9. Boiko, V. S. Pidzemna hidrohazomekhanika [Text] / V. S. Boiko, R. V. Boiko. - Lviv: Apriori, 2005. - 451 p.

10. Vecherik, R. L. Matematicheskoe modelirovanie protsessa dvizheniia gaza v sisteme plast podzemnogo hranilishcha gaza magistral'nyi gazoprovod [Text] / R. L. Vecherik, Ya. D. Pianilo, M. G. Prytula, Yu. B. Haetskii // Neft' i gaz. - 2004. No. 6. - P. 83-89.

11. Prytula, N. M. Rozrakhunok rezhymiv roboty Bilche-Volytsko-Uherskoho pidzemnoho skhovyshcha hazu (prohramnyi kompleks) [Text] / N. M. Prytula, M. H. Prytula, R. Ya. Shymko,
S. V. Hladun // Pipeline\&Gas Journal. - 2013. - No. 3. P. $36-41$.

12. Vasilev, V. A. Otsenka koeffitsientov vihrevyh soprotivlenii v uravnenii fil'tratsii gaza [Text] / V. A. Vasilev, S. Yu. Borhovich, V. I. Shamshin // Problemy kapitalnogo remonta skvazhin, ekspluatatsii podzemnyh hranilishchgaza i ekologii. - 2002. Vol. 36. - P. 61-65.

\section{МАТЕМАТИЧЕСКОЕ МОДЕЛИРОВАНИЕ РЕЖИМОВ РАБОТЫ ПОДЗЕМНЫХ ХРАНИЛИЩ ГАЗА}

Предложены математические модели газовых потоков в основных технологических объектах и модель структуры подземного хранилища газа. Приведены содержательные постановки режимно-технологических задач и факторы влияния на точность их решения. Разработано математическое обеспечение, результаты апробации которого подтвердили достаточный уровень близости рассчитанных и измеренных режимных параметров для всех газохранилищ Украины.

Ключевые слова: математические модели газовых потоков, подземное хранилище газа, компрессорная станция.

Prytula Nazar, PhD, Department of Disigning Systems of Optima Scheduling and Forecasting Operating Modes of GTS, Research and Design Institute of Gas Transport of PJSC «Ukrtransgaz», Kharkiv, Ukraine, e-mail: nazar.prytula1@gmail.com, ORCID: http://orcid. org/0000-0001-9451-275X

Prytula Myroslav, PhD, Department of Disigning Systems of Optimal Scheduling and Forecasting Operating Modes of GTS, Research and Design Institute of Gas Transport of PJSC «Ukrtransgaz», Kharkiv, Ukraine, e-mail: myroslav.prytula@gmail.com, ORCID: http:// orcid.org/0000-0001-9259-4114

Boyko Rostyslav, PhD, Head of the Underground Gas Storage Department, Regional Pipeline Division «Lvivtransgaz» of PJSC «Ukr transgaz»,Lviv, Ukraine, e-mail: rboyko25@gmail.com, ORCID: http:// orcid.org/0000-0002-6324-6847 